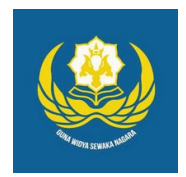

Jurnal Analogi Hukum

Journal Homepage: https://ejournal.warmadewa.ac.id/index.php/analogihukum

\title{
Pelaksanaan Perjanjian Kredit dengan Jaminan Sertifikat Deposito Pada PT. Bank BRI Cabang Mataram
}

\author{
I Putu Bayu Aditya Nendra*, I Nyoman Putu Budiartha dan Ni Gusti Ketut Sri Astiti \\ Universitas Warmadewa, Denpasar-Bali, Indonesia \\ *putubayuadityanendra@yahoo.com
}

\begin{abstract}
How To Cite:
Nendra, I, P, B, A, N., Budiartha, I, N, P., Astiti, N, G, K, S, A.(2020). Pelaksanaan Perjanjian Kredit dengan Jaminan Sertifikat Deposito Pada PT. Bank BRI Cabang Mataram. Jurnal Analogi Hukum 2 (3). 293-298. Doi: https://doi.org/10.22225/ah.2.3.2496.293-298
\end{abstract}

\begin{abstract}
The deposit certificate according to bank Indonesia is proof of the debt issued by the bank for the amount of money entrusted to him for a certain period of time. Certificates of deposit issued can be purchased at per-sale at any time and can be played for a bank loan as well as PT. BRI Bank pays the mortgage by holding the original certificate of deposit guaranteed until the credit facility is paid off. The formulation of the problem in this study is as follows: how is the implementation of the credit agreement with collateral for deposit certificates at PT. BRI Bank Mataram Branch Office and how the legal consequences and method of settlement if the term deposit certificate has been completed, while the credit agreement is still running. In this study empirical legal research was used. The results of the discussion in this study are as follows: Implementation of credit agreements with collateral for deposit certificates at PT. BRI BANK Mataram Branch Office is carried out with several stages of the process that must be done to become a debtor at PT. $B R I B A N K$, namely applying for credit, and signing credit. In implementing credit agreements with collateral/ collateral for deposit certificates at PT. BRI BANK prospective borrowers must have deposits in their own name, not on behalf of other people. The way to settle a deposit certificate with a shorter period of time compared to a credit agreement is where the bank will change the form of a certificate of deposit into an ARO (Auth Roll Over) certificate so that when the deposit certificate is due, the time period will automatically adjust to the credit period and the reimbursement are with the knowledge of the customer, if the debtor wants to apply for a loan with a guarantee of a certificate of deposit.
\end{abstract}

Keywords: Credit Agreement; Certificate; Deposit Guarantee.

Abstrak-Bank Indonesia memberikan pengertian bahwa Surat deposito ialah alat bukti yang berupa surat hutang yang dikeluarkan oleh pihak bank atas sejumlah uang yang sudah dipercayakan kepadanya dalam jangka waktu tertentu. Sertifikat deposito dikeluarkan dapat di perjual belikan sewaktu-waktu dan dapat di mainkan untuk suatu kredit bank seperti halnya PT. Bank BRI melakukan pengikatan gadai dengan menahan asli sertifikat deposito yang dijaminkan sampai fasilitas kreditnya lunas. Rumusan masalah dalam penelitian ini sebagai berikut: bagaimanakah pelaksanaan perjanjian kredit dengan agunan sertifikat deposito di PT. Bank BRI Kantor Cabang Mataram dan bagaimana akibat hukum dan cara penyelesaian apabila sertifikat deposito jangka waktunya telah selesai, sedangkan perjanjiankreditnya masih berjalan. Dalam penelitian ini digunakan Penelitian hukum empiris. Hasil pembahasan dalam penelitian ini sebagai berikut: Pelaksanaan perjanjian kredit dengan agunan sertifikat deposito di PT. BANK BRI Kantor Cabang Mataram dilakukan dengan beberapa proses tahapan yang harus dilakukan untuk menjadi debitur pada PT. BANK BRI yaitu mengajukan permohonan kredit, dan penandatanganan kredit. Dalam pelaksanaan perjanjian kredit dengan jaminan/agunan sertifikat deposito pada PT. BANK BRI calon debitur harus mempunyai deposito yang atas namanya sendiri, bukan atas nama orang lain. Cara penyelesaian sertifikat deposito yang jangka waktunya lebih pendek dibandingkan dengan perjanjian kreditnya adalah dimana pihak bank akan mengganti bentuk sertifikat deposito menjadi sertifikat deposito berbentu ARO (Authomatic Roll Over) sehingga pada saat sertifikat deposito tersebut jatuh tempo maka jangka waktunya akan di tambah dengan sendirinya menyesuaikan dengan jangka waktu kreditnya dan penggantianya tersebut dengan sepengetahuan nasabah, bila debitur ingin mengajukan pinjaman kredit dengan jaminan sertifikat deposito.

Kata Kunci: Perjanjian Kredit; Jaminan Sertifikat; Deposito.

Jurnal Analogi Hukum, Volume 2, Nomor 3, 2020. CC-BY-SA 4.o License 


\section{Pendahuluan}

Menurut pasal 1 angka 11 Undang-Undang No. 10 tahun 1998 tentang perbankan pengertian kredit adalah :

"Penyediaan uang atau tagihan yang dapat dipersamakan dengan itu, berdasarkan persetujuan atau kesepakatan pinjam meminjam antara bank dengan pihak lainya yang mewajibkan pihak meminjam untuk melunasi utangnya setelah jangka waktu tertentu dengan pemberian bunga".

Jadi kredit ialah penyedian uang atau tagihan yang dapat memiliki kesamaan berdasarkan persetujuan dan kesepakatan pinjam meminjam antara bank dengan para pihak dalam hal mana pihak meminjam memiliki kewajiban untuk melunasi hutangnya sesudah jangka waktu tertentu dengan jumlah bunga yang telah di tetapkan. Kebutuhan akan kredit mempunyai berbagai corak alasan dan latar belakang. Perorangan, perusahaan, negara atau bangsa di dunia ini mempunyai berbagai kepentingan dan alasan untuk berusaha dengan aneka jalan mendapatkan kredit (PS, 2014).

Dari permasalahan diatas tampak bahwa hukum dalam pemberian kredit dengan hal ini bank (kreditur) dan penerima kredit dalam hal ini nasabah (debitur) didasarkan kepada perjanjian yang dalam praktik perbankan dikenal sebagai perjanjian sebagai perjanjian kredit bank. Perjanjian tersebut terdiri dari perjanjian pokok yaitu perjanjian utang piutang dan diikuti dengan perjanjian tambahan berupa perjanjian pemberian jaminan oleh pihak debitor (Wastu, 2017).

Dalam hukum perbankan pasal 8 ayat (1) di kemukakan bahwa kredit atau pembayaran yang diberikan oleh bank memiliki resiko, sehingga didalam pelaksanaannya bank juga harus memperhatikan asas perkreditan dan pembiayaan dalam artian keyakinan atas kemampuan dan kesanggupan dari debitur untuk melunasi kewajibannya sesuai dengan yang janjikan dan merupakan faktor penting yang harus di perhatikan oleh pihak bank.

Guna mendapatkan kepercayaan tersebut, sebelum pihak bank memberikan kredit harus melakukan penilaian terhadap kemampuan, modal, watak, aguan, dana prospek usaha dari para nasabah debitur. Mengingat bahwa agunan sebagai salah satu unsur pemberian kredit maka apabila berdasarkan unsure-unsur lain telah dapat di peroleh keyakinan atas kemapuan nasabah debitur mengembalikan hutangnya, agunan hanya dapat berupa barang, proyek, atau hak tagihan yang di biayai dengan kredit yang bersangkutan. Bank tidak wajib meminta agunan berupa barang yang tidak berkaitan langsung dengan obyek yang dibiayai, yang lazim dikenal dengan agunan tambahan. Masalah yang timbul dimana jangka waktu sertifikat deposito yang digunakan sebagai agunan lebih pendek dari pada jangka waktu hutangnya, maka perlu diadakan penelitian.

Pengertian Surat deposito menurut bank Indonesia ialah bukti tanda hutang yang dikeluarkan oleh bank atas sejumlah uang yang dipercayakan oleh debitur untuk jangka waktu tertentu. Surat deposito dikeluarkan dapat di perjual belikan sewaktu-waktu dan dapat di mainkan untuk suatu kredit bank seperti halnya PT. Bank BRI melakukan pengikatan gadai dengan menahan asli surat deposito yang diberikan sampai fasilitas kreditnya lunas. Dalam hal ini tidak diperlukan surat kuasa, namun untuk membuktikan bahwa bank menahan sertifikat depositonya secara sah, maka nasabah harus menandatangani surat kuasa pencairan sertifikat deposito (Badrulzaman, 1991).

Penelitian tentang pengambilan kredit dalam penjaminan surat deposito di PT. Bank BRI Kantor Cabang Mataram di lakukan karena :

Kredit semacam itu berpotensi untuk melakukan kegiatan dan pengembangan usaha.

Kredit dengan jaminan sertifikat deposito lebih praktis dilaksanakan.

Hanya saja permasalahan yang, muncul apabila jangka waktu kredit berbeda dengan jangka waktu sertifikat deposito.

Berdasarkan latar belakang masalah tersebut di atas dapat dirumuskan permasalahan sebagai berikut :

Bagaimanakah pelaksanaan perjanjian kredit dengan agunan sertifikat deposito di PT. Bank BRI Kantor Cabang Mataram ?

Bagaimana akibat hukum dan cara penyelesaian apabila sertifikat deposito jangka waktunya telah selesai, sedangkan perjanjian kreditnya masih berjalan?

Secara umum penelitian ini dilakukan untuk mengetahui pelaksanaan perjanjian kredit dengan jaminan surat deposito pada PT. Bank Bri Cabang Mataramsesuai dengan peraturan perundang-undangan yang mengaturnya sedangkan secara khusus penelitian ini 
bertujuan untuk:

Untuk mengetahui mekanisme dalam membuat perjanjian kredit dengan jaminan sertifikat deposito pada PT. Bank BRI Kantor Cabang Mataram.

Untuk mengetahui hambatan dalam membuat perjanjian kredit dengan jaminan surat deposito pada PT. Bank BRI Kantor Cabang Mataram.

\section{Metode}

Tipe penelitian yang dipergunakan adalah penelitian hukum empiris. Adapun pendekatan yang digunakan dalam penulisan ini adalah sosiologi hukum Data yang digunakan dalam penelitian ini adalah data primer dan data sekunder. Teknik Pengumpulan data yang digunakan dalam penelitian ini adalah: Teknik wawancara, Teknik Studi Dokumen dan Teknik Observasi/Pengamatan. Data keseluruhan yang dikumpulkan berupa data primer dan data sekunder, selanjutnya akan diolah dan dianalisis melalui peyusunan data yang secara sistematis, diklasifikasikan, dan juga dihubungkan antara satu data dengan data lainnya. Setelah dilakukannya analisis secara kualitatif kemudian data akan disajikan secara deskriptif kualitatif dan sistematis.

\section{Hasil Penelitian Dan Pembahasan}

\section{Pelaksanaan Perjanjian Kredit dengan Agunan Sertifikat Deposito di PT. Bank BRI Kantor Cabang Mataram}

Deposito juga disebut sebagai tabungan berjangka yang mempunyai sifat hampir mirib dengan tabungan, akan tetapi memberikan suku bunga yang lebih tinggi. Pengertian deposito merupakan sebuah produk simpanan sejenis investasi sederhana dari pihak bank memberikan suku bunga tetap dalam jangka waktu tertentu. Dengan memberikan suku bunga yang relative tinggi dalam jangka waktu tersebut diharapkan para pemilik deposito setuju untuk tidak melakukan penarikan ataupun mengakses uangnya yang telah didepositokan.

Deposito tidak hanya dapat disimpan dalam bentuk rupiah. Simpan berjangka ini valas (Valuta asing) dimana dikenal dengan nama deposito valas. Jangka waktu yang di tawarkan oleh bank yaitu 1 bulan, 3 bulan, 6 bulan, 12 bulan, dan 24 bulan.

Adapun ketentuan umum yang ada dalam perjanjian kredit dengan agunan sertifikat deposito ini adalah sebagai berikut :

Sasaran kredit adalah nasabah perorangan yang memiliki sertifikat deposito yang diterbitkan oleh bank, Jangka pelayanaan adalah kredit ini diberikan kepada nasabah atau calon nasabah yang bekerja/berusaha atau bertempat tinggal di lokasi yang secara ekonomis masih berada dalam jangkauan operasional cabang, Valuta kredit, Limit kredit di hitung atas dasar nilai transaksi perekonomian nasabah, Penarikan dan pengembalian kredit, Jangka waktu, Suku Bunga, Provisi kredit dan biaya-biaya, Pelunasan sebelum jatuh tempo, Peningkatan agunan.

Surat deposito termasuk jaminan kebendaan dalam artian objek jaminan baik barang bergerak maupun barang yang tidak bergerak dalam hal ini khususnya ditujukan kepada para kreditur jika dikemudian hari debitur tidak dapat melaksanakan kewajibanya dengan membayar hutangnya kepada kreditur.

Dalam pelaksanan perjanjian kredit dengan agunan gadai sertifikat deposito terdapat beberapa permsalahan diantaranya adalah :

Isi dan bentuk perjanjian yang sudah berbentuk baku atau standar dimana pihak bank yang menentukan isi perjanjian apakah tidak bertentangan dengan pasal 1338 KUHPerdata.

Di dalam hukum perjanjian di kenal dengan atas kebebasan berkontrak. Asas ini tersimpul dalam pasal 1338 ayat 1 KUHPerdata yang mengemukakan bahwa semua persetujuan yang dibuat secara sah berlaku sebagai undangundang bagi mereka yang membuatnya. Sedangkan syarat-syarat sahnya suatu perjanjian terdapat dalam pasal 1320 KUHPerdata. Pasal ini dikenal menganut asas kesepakatan (konsensualisme).

Masalahnya dengan adanya isi dan bentuk perjanjian yang telah baku atau standar apakah asas kebebasan berkontrak dan asas kesepakatan dapat diterapkan dalam hubungan hukum antara bank dengan nasabah.

Dalam pelaksanaan perjanjian kredit pihak bank telah memberi kesepakatan kepada nasabah untuk mempelajari isi dan bentuk perjanjian, sehingga asas kebebasan berkontrak dan asas kesepakatan telah di terapkan. Apabila nasabah merasa keberatan dengan isi dan bentuk perjanjian yang di berikan, ia tidak perlu menandatangani perjanjian tersebut.

Akibat Apabila Sertifikat Deposito Mempunyai 


\section{Jangka Waktu Yang Lebih Pendek, Sedangkan Perjanjian Kreditnya Masih Berjalan}

Hasil wawancara dengan Bapak I Made Arya Adi Wijaya sebagai salah satu bentuk jaminan likuid, terapat 2 (dua) sertifikat deposito menurut jenis penetapanya, yaitu :

Sertifikat deposito ARO (Authomatic Roll Over), merupakan perpanjangan waktu deposito yang melalui computer secara otomatis.

Sertifikat deposito Non ARO, yaitu perpanjangan jangka waktu deposito yang tidak dilakukan secara otomatis tetapi dengan menunggu pemberitahuan dari nasabah.

Menurut keterangan dari Bapak Made Arya bagian kredit PT. BANK BRI Cabang Mataram, bahwa apabila sertifikat deposito berbentuk ARO (Authomatic Roll Over) dijadikan sebagai jaminan kredit, maka jangka waktunya dapat diperpanjang secara otomatis sesuai dengan jangka waktu kreditnya. Apabila yang dijaminkan sertifikat deposito Non ARO yang dijadikan sebagai jaminan kredit, pihak Bank akan mengganti menjadi deposito berbentuk ARO pada saat jatuh tempo jangka waktu deposito dengan sepengetahuan nasabah, bila ingin mengajukan perpanjangan kredit dengan jaminan sertifikat deposito.

Nasabah penabung deposito pada saat datang ke bank untuk menabung dalam bentuk deposito, oleh pihak bank akan diberikan formulir yang harus di isi dimana di dalam formulir itu antara lain tercantum klasula, nominal deposito, jangka waktu, suku bunga, dan bentuk deposito tersebut apakah ARO (Authomatic Roll Over) atau tidak serta klasula lainya yang mencantumkan bahwa deposito tidak boleh ditarik sebelum jangka waktunya deposito jatuh tempo.

Jadi dalam perjanjian kredit apabila jaminan yang diberikan yaitu sertifikat deposito memiliki jangka waktu yang lebih pendek dibandingkan dengan perjanjian kreditnya tidak akan berakibat hukum apapn apabila jaminan gadai sertifikat deposito berbentuk ARO (Authomatic Roll Over). Namun apabila jminan gadai sertifikat deposito tersebut tidak berbentuk Authomatic Roll Over maka pihak bank akan menggatinya menjadi Authomatic Roll Over pada saat jangka waktu depositonya jatuh tempo dengan sepengetahuan nasabah. Nila nasabah memang ingin menjaminkan sertifikat deposito untuk kredit. perjanjian kredit harus dituangkan dalam bentuk tertulis yang umumnya dibuat secara notaril dan di bawah tangan. Sehingga pelaksanaan perjanjian kredit dengan jaminan sertifikat deposito di PT. BANK NRI dilakukan dengan pengikatan di bawah tangan.

Pengikatan jaminan tersebut dilaksanakan dengan persetujuan gadai atas tagihan tunai, surat kuasa untuk memblokir dan mencairkan serta perjanjian kredit.

Jadi walaupun secara admistrasi proses pemberian kredit telah selesai, namum tugas bank tetap melakukan pengawasan atas kredit yang diberikan. Hal ini menunjukan bahwa sebelum dan sesudah kredit diberikan, merupakan suatu langkah pengamanan yang dilakukan oleh bank.

Sesuai dengan kebijakan perkreditan PT. BANK BRI/ credit policy, cara-cara yang dimiliki PT. BANK BRI untuk mengamankan kredit adalah :

Pengamanan Preventif, yaitu pihak bank meminta bilyet deposito untuk disimpan oleh bank sebagai jaminan kredit dan juga meminta debitur untuk mengisi permohonan pemblokiran dan bunga deposito langsung agar masuk ke rekening bank sebagai bunga atas pinjaman kredit tersebut.

Pencairan deposito, yaitu deposito langsung dicairakan karena tidak membayar pinjaman kredit.

Jadi dengan demikian tindakan pengamanan kredit dengan jaminan deposito dilakukan oleh bank karena merasa yakin kredit itu pasti kembali dan resiko bias dihindari dengan kata lain resikonya relative kecil.

Bila debitur telah tiada, maka seluruh hutang dan kewajiban debitur yang timbul dimana perjanjian ini dan hutang-hutang yang akan timbul di kemudian hari, baik yang dibuat secara notaries maupun dibawah tangan oleh debitur kepada bank merupakan hutang dan kewajiban para ahli waris dari debitur dan terhadap hutang-hutang dan kewajiban mana pelunasanya tidak dapat di bagi-bagi antara para ahli waris debitur.

Bilamana penjamin telah tiada maka seluruh kewajiban penjamin yang timbul berdasarkan perjanjian ini atau yang akan timbul di kemudian hari yang dibuat secara notaris maupun di bawah tangan oleh penjamin kepada bank, merupakan kewajiban para hali waris dari penjamin.

Dalam prakek perbankan pelaksanaan 
PT. BANK BRI setiap akhir bulan akan meneliti nasabah debitur yang belum membayar angsuran kreditnya dan bunganya, yang disebabkan beberapa hal, diantaranya:

Nasabah belum mempunyai uang untuk mengangsur pinjamanya.

Nasabah lupa akan kewajiban untuk mengangsur pinjamanya.

Nasabah meninggal dunia.

Di dalam klasula/perjanjian kredit pihak bank biasanya mewajibkan kepada debitur khususnya debitur perorangan untuk mengikuti asuransi jiwa sehingga apabila debitur meninggal dunia sebelum jangka waktu kredit berakhir, maka kreditnya akan di bayar oleh pihak asuransi.

Apabila dalam perjanjian kredit tidak mencantumkan klasula asuransi jiwa dan nasabah debitur meninggal dunia, sedangkan jangka waktu gadai sertifikat deposito belum berkahir maka penyelesaiannya adalah ahli waris diminta untuk melunasi hutangnya pewaris (debitur), jika ahli waris bersedia melunasi hutang si debitur, maka sertifikat deposito akan di serahkan kepada ahli waris, namum apabila ahli waris tidak bersedia melunasi hutang debitur, maka bank akan mencairkan sertifikat deposito setelah jangka waktu berakhirnya sertifikat deposito, apabila terdapat sisa, maka sida tersebut akan di berikan kepada ahli waris.

Dalam perjanjian gadai yang merupakan perjanjian jaminan di situ dinyatakan dalam perjanjian tersebut bahwa pihak PT. BANK BRI berhak mengambil pelunasan dari simpanaan deposito milik debitur yang dicairkan berdasarkan surat kuasa yang di berikan oleh debitur kepada PT. BANK BRI. Berdasarkan pasal 1155-1156 KUH Perdata yang menjadi dasar hukum dalam melakukan eksekusi jaminanya, apabila dalam jangka waktu yang telah di tentukan setelah penagihan debitur tidak memenuhi kewajibannya yaitu pembayaran pinjamaan kredit.

PT. BANK BRI setiap awal bulan akan mengirimkan rekening Koran kepada debitur dimana di dalamnya tercantum jumlah perhitungan kredit pihak debitur. Rekening Koran tersebut berisi mutasi pembukaan harian pengambilan dan penyetoran yang dilakukan oleh debitur, rekening Koran tersebut dikirimkan oleh PT. BANK BRI ke alamat debitur yang juga merupakan bukti tertulis dari bank kepada debitur tentang mutasi pengembalian dan mutasi penyetoran periode awal sampai dengan akhir bulan. Pencairan sertifikat deposito milik debitur yang dijaminkan kepada PT. BANK BRI di lakukan oleh PT. BANK BRI sendiri yang dilakukan saat jatuh tempo dan itu merupakan wewenang PT. BANK BRI selaku kreditur. Hal demikian merupaka hak dari pihak bank selaku kreditur yang dilakukan tanpa adanya title eksekurial, tanpa butuh juru sita dan tanpa melalui pengadilan.

PT. BANK BRI mencairkan sertifikat deposito berdasarkan surat kuasa yang dibuat/ diberikan oleh debitur. Tanpa adanya surat kuasa tersebut pihak bank tidak dapat mencairkan sertifikat deposito yang dijadikan sebagai agunan. Surata kuasa untuk mencairkan tersebut adalah surat yang member hak kepada PT. BANK BRI selaku kreditur yang mencairkan, kemudian PT. BANK BRI mengambil pelunasan dari deposito yang telah di cairkan tersebut untuk dimasukan ke dalam rekening pinjmanan dan sisa dari uang deposito tersebut akan diserahkan kepada debitur.

Surat kusa yang dipergunakan pihak PT. BANK BRI dalam mengeksekusi benda yang di jadikan agunan adalah surat yang pokoknya hanya memberikan kewenangan kepada pihak yang diberi kuasa yang dalam hal ini pihak PT. BANK BRI untuk mencairkan sertifikat deposito tersebut, penulis berpendapat bahwa surat kuasa bukanlah dasar pengeksekusi, surat kuasa hanya member wewenang untuk mencairkan deposito apabila debitur wanprestasi.

\section{Simpulan}

Berdasarkan uraian tersebut diatas dapatlah ditarik simpulan sebagai berikut :

Pelaksanaan perjanjian kredit dengan agunan sertifikat deposito di PT. BANK BRI Kantor Cabang Mataram dilakukan dengan beberapa proses tahapan yang harus dilakukan untuk menjadi debitur pada PT. BANK BRI yaitu mengajukan permohonan kredit, dan penandatanganan kredit.

Dalam pelaksanaan perjanjian kredit dengan jaminan/agunan sertifikat deposito pada PT. BANK BRI calon debitur harus mempunyai deposito yang atas namanya sendiri, bukan atas nama orang lain.

Pengikat dalam pelaksanaan perjanjian kredit dengan jaminan/agunan sertifikat deposito pada PT. BANK BRI dilakukan dengan gadai yang dinyatakan dalam perjanjian gadai dan dilakuka bahwa tangan. 
Cara penyelesaian sertifikat deposito yang jangka waktunya lebih pendek dibandingkan dengan perjanjian kreditnya adalah dimana pihak bank akan mengganti bentuk sertifikat deposito menjadi sertifikat deposito berbentu ARO (Authomatic Roll Over) sehingga pada saat sertifikat deposito tersebut jatuh tempo maka jangka waktunya akan di tambah dengan sendirinya menyesuaikan dengan jangka waktu kreditnya dan penggantianya tersebut dengan sepengetahuan nasabah, bila debitur ingin mengajukan pinjaman kredit dengan jaminan sertifikat deposito. Dan apabila debitur wanprestasi penangananya cukup mudah dengan mencairkan sertifikat deposito tersebut.

\section{Daftar Pustaka}

Badrulzaman, M. D. (1991). Bab-bab tentang Credieverband, Gadai dan Fiducia. Bandung: Citra Aditya Bakti.

PS, B. C. (2014). Pengamanan Pemberian Kredit Bank Dengan Jaminan Hak Guna Bangunan. Cita Hukum, 1(2). Retrieved from http:// journal.uinjkt.ac.id/index.php/ citahukum/article/download/1468/pdf

Wastu, I. B. G. G. (2017). Kekuatan Hukum Perjanjian Kredit Di Bawah Tangan Pada Bank Perkreditan Rakyat. Jurnal Ilmiah Prodi Magister Kenot Ariatan, 1. Retrieved from https://ojs.unud.ac.id/ index.php/ActaComitas/article/ download/34260/20616/\#: :text=Salah satu dasar yang cukup,mewajibkan pihak peminjam untuk melunasi

Undang-Undang No. 10 tahun 1998 tentang perbankan 